\title{
Hepatitis $C$ virus seroprevalence in the general female population of 9 countries in Europe, Asia and Africa
}

Gary M. Clifford ${ }^{1 *}$, Tim Waterboer ${ }^{2}$, Bolormaa Dondog ${ }^{2}$, You Lin Qiao ${ }^{3}$, Dimitri Kordzaia ${ }^{4}$, Doudja Hammouda ${ }^{5}$, Namory Keita ${ }^{6}$, Nahid Khodakarami, Syed Ahsan Raza ${ }^{8,9}$, Ang Tshering Sherpa ${ }^{10}$, Witold Zatonski ${ }^{11}$,

Michael Pawlita ${ }^{2}$, Martyn Plummer ${ }^{1}$ and Silvia Franceschi ${ }^{1}$

\begin{abstract}
Background: New oral treatments with very high cure rates have the potential to revolutionize global management of hepatitis $\mathrm{C}$ virus $(\mathrm{HCV})$, but population-based data on HCV infection are missing in many low and middle-income countries (LMIC).

Methods: Between 2004 and 2009, dried blood spots were collected from age-stratified female population samples of 9 countries: China, Mongolia, Poland, Guinea, Nepal, Pakistan, Algeria, Georgia and Iran. HCV antibodies were detected by a multiplex serology assay using bead-based technology.

Results: Crude HCV prevalence ranged from $17.4 \%$ in Mongolia to $0.0 \%$ in Iran. In a pooled model adjusted by age and country, in which associations with risk factors were not statistically heterogeneous across countries, the only significant determinants of HCV positivity were age (prevalence ratio for $\geq 45$ versus $<35$ years $=2.84,95 \% \mathrm{Cl} 2.18-3.71$ ) and parity (parous versus nulliparous $=1.73,95 \% \mathrm{Cl} 1.02-2.93$ ). Statistically significant increases in HCV positivity by age, but not parity, were seen in each of the three countries with the highest number of HCV infections: Mongolia, Pakistan, China. There were no associations with sexual partners nor HPV infection. HCV prevalence in women aged $\geq 45$ years correlated well with recent estimates of female HCV-related liver cancer incidence, with the slight exception of Pakistan, which showed a higher HCV prevalence (5.2\%) than expected.

Conclusions: HCV prevalence varies enormously in women worldwide. Medical interventions/hospitalizations linked to childbirth may have represented a route of HCV transmission, but not sexual intercourse. Combining dried blood spot collection with high-throughput HCV assays can facilitate seroepidemiological studies in LMIC where data is otherwise scarce.
\end{abstract}

Keywords: Hepatitis C virus, Epidemiology, Serology, Liver cancer

\section{Background}

About 180 million people, some 3\% of the world's population, are estimated to have been exposed to hepatitis $\mathrm{C}$ virus (HCV) [1-3]. Of these, $130-150$ million ( 80\%) are chronically $\mathrm{HCV}$ infected and at risk for development of hepatitis- $C$ related liver cirrhosis or cancer, which kill approximately 700,000 people each year [4]. Although new $\mathrm{HCV}$ treatments offering very high cure

\footnotetext{
* Correspondence: clifford@iarc.fr

${ }^{1}$ International Agency for Research on Cancer, 150 cours Albert Thomas, 69372 Lyon Cedex 08, France

Full list of author information is available at the end of the article
}

rates with short durations and few side effects have the potential to drastically reduce $\mathrm{HCV}$-related mortality, access to diagnosis and expensive treatment remain low, so that the number of people living with $\mathrm{HCV}$ is actually reported to be increasing [1].

In 2016, the World Health Assembly adopted a strategy to eliminate viral hepatitis as a major public health threat by 2030 , noting that national data on hepatitis virus infection are often lacking [5]. In addition, available HCV surveys often over-represent low-risk groups, particularly younger low-risk persons (e.g. pregnant women and blood donors), whereas $\mathrm{HCV}$ prevalence is known 
to increase steadily with age owing to the combination of accumulating risk of exposure and a high probability of infection becoming chronic [6].

Common routes of $\mathrm{HCV}$ infection are unsafe injections, inadequate sterilization of medical equipment, and the transfusion of unscreened blood and blood products that have been common in high-income countries till the 1980s and also more recently in low- and mediumincome countries (LMIC). Because these practices are largely specific to a given country's medical system, $\mathrm{HCV}$ prevalence and the timing of infection spread may differ between bordering countries [2], and national level data on $\mathrm{HCV}$ infection is required to inform public health decisions.

Hence, we exploited a series of standardized seroepidemiological surveys in order to describe HCV prevalence and risk factors among the general female population of a heterogeneous range of countries around the world. HCV seropositivity was determined using a high throughput assay that has been shown to provide an accurate and cost-effective tool for assessment of HCV antibodies in large epidemiologic studies [7], and we went on to compare country-specific $\mathrm{HCV}$ prevalence with recently generated country-specific estimates of HCV-related liver cancer incidence.

\section{Methods}

\section{Population}

Between 2004 and 2009, studies were undertaken in 11 areas in 9 countries with the primary aim to estimate the prevalence of genital human papillomavirus virus (HPV) infection, according to a similar protocol developed and co-ordinated by the International Agency for Research on Cancer (IARC). Population sampling methods have been previously described for the individual study centres: Shanxi, China [8]; Shenyang, China [9]; Shenzhen, China [10]; Ulaanbaatar, Mongolia [11]; Warsaw, Poland [12]; Conakry, Guinea [13]; Bharatpur, Nepal [14]; Karachi, Pakistan [15]; Zeralda, Algeria [16]; Tbilisi, Georgia [17]; and Tehran, Iran [18]. In each area, an attempt was made to obtain an age-stratified population-based sample that included at least 100 women in each 5-year age group, from 15-19 up to 65 years and older. The number of included women is sometimes higher than that in the original reports due to relaxing of selection criteria for adequacy of genital specimens. Data from Mongolia have been previously reported in validation studies of the present HCV serological assay $[7,19]$. Trained interviewers administered a face-to-face questionnaire that included information on sociodemographic characteristics, sexual behaviour, reproductive and contraceptive history, and smoking habits. All participants signed informed consent forms according to the recommendations of the IARC Ethics
Committee, and of the local ethical review committees in each of the participating countries, which also approved each of the original studies.

\section{Specimen collection}

Each participant had a blood sample collected by venopuncture. In Mongolia, this sample was drawn from the cubital fossa into vacuum containers without anticoagulant [19], whereas in all other areas, samples were obtained by fingerstick. In both instances, full blood was then immediately applied to DBS (dried blood spot) filter paper card (Whatman 903 Protein Saver Blood Collection Cards; Schleicher \& Schuell) to entirely fill five $14.5 \mathrm{~mm}$ diameter circles. DBS cards were dried at room temperature, placed in separate plastic paper zip lock envelopes containing a silica desiccant, and shipped at ambient temperature to the German Cancer Research Center (DKFZ) in Heidelberg, Germany, and stored at $-20^{\circ} \mathrm{C}$ until serological analysis.

Study participants were also invited for a pelvic examination (although a subset, particularly selfreported virgins, declined) and collection of cervical exfoliated cells for HPV DNA testing, performed in the Department of Pathology, VU University Medical Center, Amsterdam, the Netherlands, according to a general primer GP5+/6+-mediated PCR [20].

\section{HCV serology}

Antibodies were eluted from DBS cards according to a previously reported protocol that has been shown to result in high agreement ( $>96 \%$ for HCV antigens) of seropositivity in paired DBS and serum results [19]. In brief, one punch of $6 \mathrm{~mm}$ diameter from each DBS was eluted in one well of a 96-well plate in $100 \mu \mathrm{L}$ PBS at $4^{\circ} \mathrm{C}$ overnight, and $16 \mu \mathrm{l}$ of eluate subsequently mixed with 80 $\mu \mathrm{L}$ DBS preincubation buffer.

A multiplex serology assay [19] including antigens to HCV (strain H77, subtype 1a) Core and NS3 proteins was performed as previously described [7]. In brief, full-length coding sequences of Core and NS3 were expressed as double fusion proteins with an $\mathrm{N}$ terminal-GST and a C-terminal tag epitope derived from the large T-antigen of SV40 in E. coli. Fusion proteins were loaded and affinity-purified on glutathionecasein coupled spectrally distinct fluorescence-labeled polystyrene beads (SeroMap; Luminex). DBS eluates were incubated with pooled antigen loaded bead sets. Bound antibodies were quantified with biotinylated goat antihuman IgA, IgM, IgG (Dianova), and R-phycoerythrin-labeled streptavidin in a Luminex 100 analyzer as the median R-phycoerythrin fluorescence intensity (MFI) from at least 100 beads of the same bead set. Antigen-specific MFI values were calculated as previously described [21]. 
DBS-specific cut-off values for HCV Core (MFI $\geq 967$ ) and NS3 (MFI $\geq 310)$ were defined as the mean MFI plus three SDs from 235 reference sera that tested negative by a commercial HCV antibody screening assay [19]. Women that were positive for both Core and NS3 proteins were defined as being $\mathrm{HCV}$-positive. In an evaluation against a set of 432 reference sera, this cut-off has been proven to perform similarly, in a single step, to a commercial HCV antibody screening assay (MEIA) followed by RNA confirmation (98\% sensitivity, $99 \%$ specificity) [7].

When a subset of 2,988 DBS samples from 8 study areas were re-tested on a second occasion to evaluate assay reproducibility, 2,982 (99.8\%) were concordantly classified (2,940 HCV-negative, $42 \mathrm{HCV}$-positive).

\section{Statistical analyses}

HPV prevalence was standardized by age using the world standard population (in 5-year age groups from 15-19 to 60-65 years) as a reference [22]. Prevalence ratios (PR) for HCV seropositivity and corresponding 95\% confidence intervals $(\mathrm{CI})$ were calculated using unconditional logistic regression adjusted for age (5-year groups) and study area. Heterogeneity of PRs between study areas was tested by calculating the difference between the log likelihood of the model that considered the interaction term between the areas and risk factor of interest and the log likelihood of the model that included the exposure only, and comparing it to the chi-squared distribution with degrees of freedom equal to the number of areas minus one.

Country-specific estimates of HCV-related liver cancer incidence in women were extracted from Plummer et al, Lancet Global Health, 2016 [23], derived by combining country-specific estimates of $\mathrm{HCV}$ attributable fraction in liver cancer with Globocan 2012 [24] estimates of female liver cancer incidence.

\section{Results}

HCV serology results were obtained for a total of 12,204 women, with study-specific sample sizes varying from 1,516 for Shenzhen, China, down to 892 for Iran (Table 1). Overall median age was 34 years, varying from 30 to 38 years by study center (Table 1 ). A total of 274 women $(2.2 \%)$ were HCV-positive. Crude HCV prevalence ranged from $17.4 \%$ in Mongolia down to $0.0 \%$ in Iran (Table 1). Age-standardization reduced HCV prevalence estimates (by increasing the relative weight of younger age groups, who were less often HCV-positive), but did not change relative differences in $\mathrm{HCV}$ positivity between centers.

Table 2 shows the relationship of selected characteristics of study women with HCV positivity. In a model adjusted by age and study area, as appropriate, the only significant determinants of $\mathrm{HCV}$ positivity were age group (PR for $\geq 45$ versus $<35$ years $=2.84,95 \%$ CI 2.18 3.71 ) and parity (PR for parous versus nulliparous $=1.73$, 95\% CI 1.02-2.93). However, no risk trend was found by number of births. Associations of $\mathrm{HCV}$ positivity with risk factors were not statistically heterogeneous across study areas ( $\mathrm{p}$ values for heterogeneity $=0.17,0.88,0.59$ and 0.25 for age, sexual partners, parity and induced abortion, respectively).

Findings by age group and parity are also shown separately for Mongolia, Pakistan and China (the three countries with the highest number of $\mathrm{HCV}$-positive women) in Table 3. Statistically significant increases in $\mathrm{HCV}$ positivity by age were seen in each of the three

Table 1 HCV prevalence by study center

\begin{tabular}{|c|c|c|c|c|c|c|c|}
\hline \multirow[b]{3}{*}{ Geographical area } & \multirow[b]{3}{*}{ Median age } & \multirow[b]{3}{*}{$\mathrm{N}$ tested } & \multirow[b]{3}{*}{$\mathrm{N}$ pos } & \multicolumn{4}{|c|}{ HCV prevalence } \\
\hline & & & & \multicolumn{2}{|c|}{ Crude } & \multicolumn{2}{|c|}{ Age-standardized $^{\mathrm{a}}$} \\
\hline & & & & $\%$ & $95 \% \mathrm{Cl}$ & $\%$ & $95 \% \mathrm{Cl}$ \\
\hline Mongolia, Ulaanbaatar & 35 & 1,075 & 187 & 17.4 & $15.2-19.2$ & 10.9 & $3.3-18.6$ \\
\hline Pakistan, Karachi & 35 & 963 & 31 & 3.2 & $2.2-4.5$ & 1.7 & $0.5-2.9$ \\
\hline Georgia, Tbilisi & 33 & 1,431 & 17 & 1.2 & $0.7-1.9$ & 0.7 & $0.0-1.4$ \\
\hline Guinea, Conakry & 30 & 1,253 & 11 & 0.9 & $0.4-1.6$ & 0.5 & $0.0-1.4$ \\
\hline Poland, Warsaw & 37 & 909 & 7 & 0.8 & $0.3-1.6$ & 0.3 & $0.0-0.9$ \\
\hline China, Shenyang & 34 & 989 & 6 & 0.6 & $0.2-1.3$ & 0.4 & $0.0-1.7$ \\
\hline China, Shanxi & 36 & 940 & 6 & 0.6 & $0.2-1.4$ & 0.3 & $0.0-0.8$ \\
\hline China, Shenzhen & 30 & 1,516 & 6 & 0.4 & $0.1-0.9$ & 0.3 & $0.0-0.6$ \\
\hline Nepal, Bharatpur & 33 & 1,061 & 2 & 0.2 & $0.0-0.7$ & 0.2 & $0.0-0.8$ \\
\hline Algeria, Zeralda & 36 & 1,135 & 1 & 0.1 & $0.0-0.5$ & 0.1 & $0.0-0.2$ \\
\hline Iran, Tehran & 38 & 892 & 0 & 0 & $0.0-0.4$ & 0.0 & $0.0-0.4$ \\
\hline Total & 34 & 12,164 & 274 & 2.2 & $2.0-2.5$ & 1.4 & $1.0-1.83$ \\
\hline
\end{tabular}




Table 2 Prevalence ratios (PR) for HCV positivity and corresponding 95\% confidence intervals (CI) according to selected women's characteristics

\begin{tabular}{|c|c|c|c|c|}
\hline Risk factor & $\mathrm{N}$ tested & $\begin{array}{l}\text { HCV positive } \\
\mathrm{N}(\%)\end{array}$ & Adjusted PR & $95 \% \mathrm{Cl}$ \\
\hline Age & 12,164 & & & \\
\hline$<35$ & 6,249 & $79(1.3)$ & 1 & - \\
\hline $35-44$ & 2,894 & $78(2.7)$ & 1.86 & $1.39-2.50$ \\
\hline$\geq 45$ & 3,021 & $117(3.9)$ & 2.84 & $2.18-3.71$ \\
\hline$x_{1}^{2}$ for trend & & & $p<0.001$ & \\
\hline Education level & 12,156 & & & \\
\hline None & 1,713 & $24(1.4)$ & 1 & - \\
\hline Primary & 1,552 & $21(1.3)$ & 0.96 & $0.52-1.77$ \\
\hline Secondary and higher & 8,891 & $229(2.6)$ & 0.86 & $0.46-1.60$ \\
\hline Lifetime number of sexual partners ${ }^{b}$ & 10,926 & & & \\
\hline 0 & 1,086 & $1(0.1)$ & 0.21 & $0.03-1.55$ \\
\hline 1 & 7,513 & $146(1.9)$ & 1 & - \\
\hline 2 & 1,305 & $60(4.6)$ & 1.12 & $0.84-1.49$ \\
\hline $3+$ & 1,022 & $65(6.4)$ & 1.08 & $0.81-1.44$ \\
\hline$x_{1}^{2}$ for trend & & & $p=0.367$ & \\
\hline Number of births (parity) & 11,199 & & & \\
\hline Nulliparous & 2,207 & $21(0.9)$ & 1 & - \\
\hline 1 & 3,228 & $55(1.7)$ & $1.68^{d}$ & $0.98-2.90$ \\
\hline 2 & 2,644 & $75(2.8)$ & $1.81^{\mathrm{d}}$ & $1.01-3.26$ \\
\hline $3+$ & 3,120 & $119(3.8)$ & $1.84^{\mathrm{d}}$ & $1.01-3.38$ \\
\hline$x_{1}^{2}$ for trend & & & $p=0.171$ & \\
\hline Induced abortion ${ }^{c}$ & 9,166 & & & \\
\hline 0 & 5,433 & $95(1.7)$ & 1 & - \\
\hline 1 & 1,750 & $46(2.6)$ & 0.97 & $0.69-1.37$ \\
\hline $2+$ & 1,983 & $112(5.6)$ & 1.24 & $0.93-1.66$ \\
\hline$x_{1}^{2}$ for trend & & & $p=0.121$ & \\
\hline Smoking status & 12,153 & & & \\
\hline Never & 10,860 & $235(2.2)$ & 1 & - \\
\hline Ever & 1,293 & $38(2.9)$ & 1.21 & $0.88-1.66$ \\
\hline HPV DNA-positive & 9,984 & & & \\
\hline No & 8,264 & $183(2.2)$ & 1 & - \\
\hline Yes & 1,720 & $65(3.8)$ & 1.04 & $0.80-1.36$ \\
\hline
\end{tabular}

${ }^{a}$ Adjusted for age (5-year groups) and geographical area, as appropriate

${ }^{b}$ Algeria excluded because of missing data

cAlgeria and Guinea excluded because of missing data

${ }^{\mathrm{d} C o m b i n e d} \mathrm{PR}$ for $\geq 1$ versus $0=1.73(1.02-2.93)$

countries, but the rise between women $<35$ to those 3544 years of age was especially steep in Pakistan. Increases in $\mathrm{HCV}$ positivity in parous women were only observed in Mongolia and Pakistan and did not meet statistical significance (Table 3).

Age-specific $\mathrm{HCV}$ prevalence estimates are shown by study country in Fig. 1, in order of highest to lowest HCV prevalence among women aged $\geq 45$ years, and are plotted against country-specific estimates of female HCV-related liver cancer incidence rates. Age-specific increases in HCV prevalence were observable in Mongolia, Pakistan, Guinea, Poland and China. HCV prevalence estimates in women aged $\geq 45$ years correlated well with female HCVrelated liver cancer incidence rates, ranging between the extremes of Mongolia (28.4\% HCV prevalence versus 20.9 cases of HCV liver cancer per 100,000 women) and Iran ( $0.0 \% \mathrm{HCV}$ prevalence versus 0.2 cases of $\mathrm{HCV}$ liver cancer per 100,000 women). The only slight exception to this 
Table 3 HCV positivity by age and number of births, separately for Mongolia, Pakistan and China

\begin{tabular}{|c|c|c|c|c|c|c|c|c|c|}
\hline \multirow[b]{2}{*}{ Risk factor } & \multicolumn{3}{|l|}{ Mongolia } & \multicolumn{3}{|l|}{ Pakistan } & \multicolumn{3}{|l|}{ China } \\
\hline & $\mathrm{N}$ tested & $\begin{array}{l}\text { HCV positive } \\
N(\%)\end{array}$ & $\begin{array}{l}\text { Adjusted } \mathrm{PR}^{\mathrm{a}} \\
\text { and } 95 \% \mathrm{Cl}\end{array}$ & $\mathrm{N}$ tested & $\begin{array}{l}\text { HCV positive } \\
N(\%)\end{array}$ & $\begin{array}{l}\text { Adjusted PRa } \\
\text { and } 95 \% \mathrm{Cl}\end{array}$ & $\mathrm{N}$ tested & $\begin{array}{l}\text { HCV positive } \\
N(\%)\end{array}$ & $\begin{array}{l}\text { Adjusted PRa } \\
\text { and } 95 \% \mathrm{Cl}\end{array}$ \\
\hline Age & 1,075 & & & 963 & & & 3,445 & & \\
\hline$<35$ & 511 & $55(10.8)$ & 1 & 479 & $7(1.5)$ & 1 & 1,915 & $5(0.3)$ & 1 \\
\hline $35-44$ & 289 & $54(18.7)$ & $1.74(1.23-2.45)$ & 254 & $12(4.7)$ & $3.23(1.29-8.11)$ & 755 & $4(0.5)$ & $2.03(0.55-7.54)$ \\
\hline$\geq 45$ & 275 & $78(28.4)$ & $2.63(1.93-3.60)$ & 230 & $12(5.2)$ & $3.57(1.42-8.95)$ & 775 & $9(1.2)$ & $4.45(1.49-13.2)$ \\
\hline$x_{1}^{2}$ for trend & & & $p<0.001$ & & & $p=0.005$ & & & $p=0.007$ \\
\hline Number of births & 1,056 & & & 955 & & & 3,225 & & \\
\hline 0 & 228 & $16(7.0)$ & 1 & 136 & $1(0.7)$ & 1 & 942 & $2(0.2)$ & 1 \\
\hline$\geq 1$ & 828 & 169 (20.4) & $1.62(0.86-3.04)$ & 819 & $30(3.7)$ & $3.06(0.39-24.1)$ & 2,283 & $16(0.7)$ & $0.48(0.06-3.82)$ \\
\hline
\end{tabular}

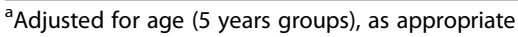

correlation was Pakistan, which showed a high $\mathrm{HCV}$ prevalence $(5.2 \%)$ in comparison to a relatively low estimate of female HCV-related liver cancer (1.3 cases per 100,000 women).

\section{Discussion}

Benefiting from a standardized population-based sampling protocol and a validated serological assay, we describe important variation in HCV seroprevalence in women around the world and robustly confirm the absence of a sexual transmission route for $\mathrm{HCV}$ infection. Crude population-based $\mathrm{HCV}$ prevalence ranged from $17 \%$ in Mongolia down to $0 \%$ in Iran and correlated with country-specific estimates of female $\mathrm{HCV}$ related liver cancer incidence, which are also highest in Mongolia (20.9 per 100,000 women) and lowest in Iran (0.2 per 100,000 women) in women aged $\geq 45$ years. Furthermore, when available, our estimates were compatible with previous population-based estimates of $\mathrm{HCV}$ prevalence in the evaluated countries.

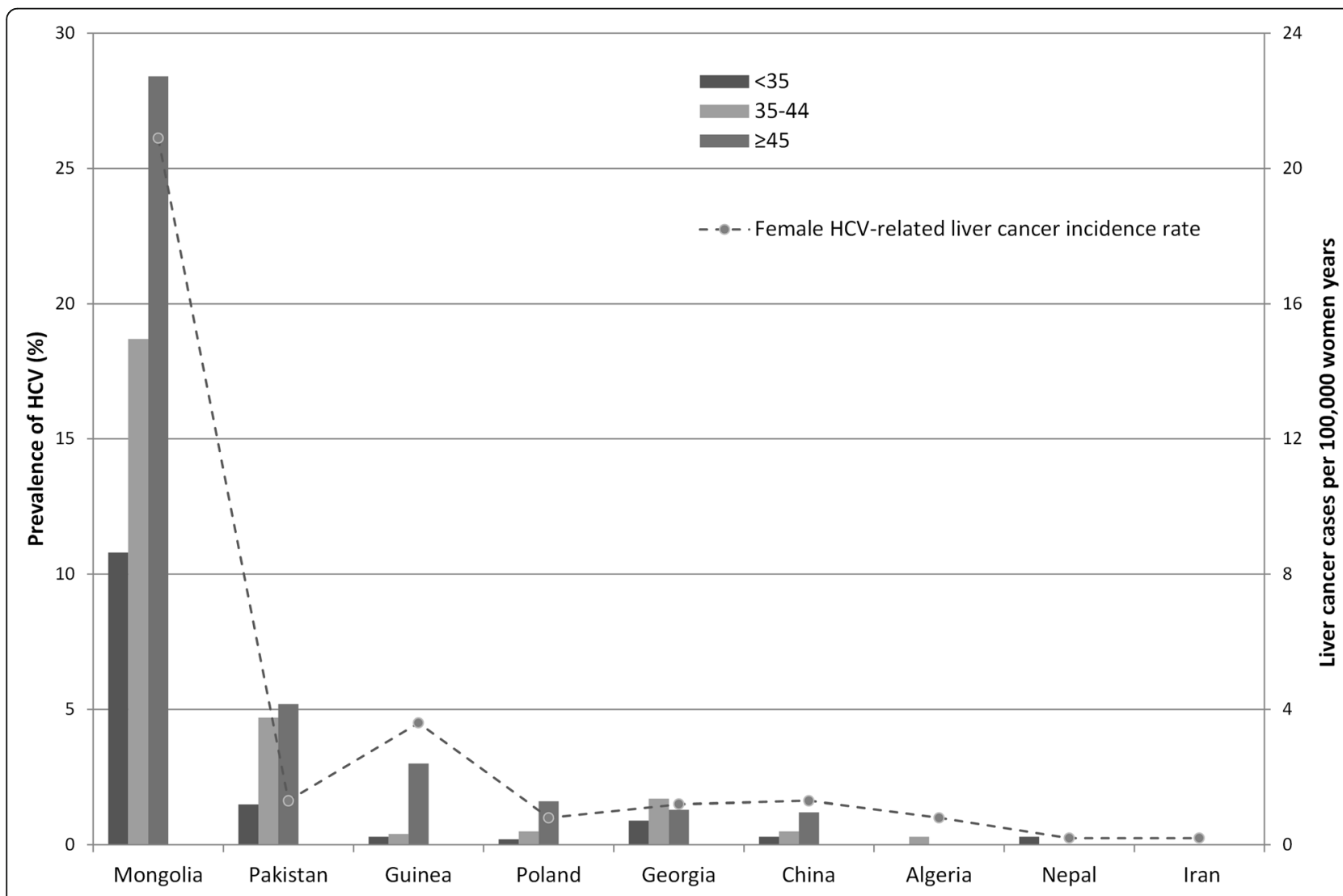

Fig. 1 Correlation of age-specific HCV prevalence with HCV-related liver cancer incidence in women $\geq 45$ years 
The extreme HCV prevalence in Mongolia was expected and has been previously described [7]. Indeed, Mongolia has the highest burden of HCV-related liver cancer in the world [23], driven by a long-lasting epidemic due to iatrogenic transmission of $\mathrm{HCV}$ through mass vaccination campaigns (e.g. smallpox, polio [25], blood transfusions $[26,27]$ ) and extensive use of injected treatments [28]. At the lower extreme, we confirm an anti-HCV prevalence of less than $1 \%$ reported from a wide-range of other population-based studies in Iran [29], where a low fraction of liver cancers are estimated to be attributable to $\mathrm{HCV}$ [30].

The relatively high HCV prevalence found in Karachi, Pakistan ( $5 \%$ in women aged $45+$ years $)$ is similar to that in previous large population-based surveys in Karachi [31, 32] and nationwide in Pakistan [33]. Indeed, $\mathrm{HCV}$ was reported to be the predominant cause of liver cancer in Pakistan [34, 35]. Given this high HCV prevalence, however, current estimates of HCV-related liver cancer incidence in Pakistani women are lower than expected. This may be due to limitations in liver cancer incidence data for Pakistan [24], or to a more recent iatrogenic spread of the virus compared to, for instance, Mongolia. Indeed the proportion of HCV-positive hepatocellular carcinoma is still increasing in Pakistan [34].

$\mathrm{HCV}$ prevalence estimates were highly consistent across the three Chinese sites (0.4-0.6\%) and compatible with estimates of $0.4-1.0 \%$ in large population-based surveys of women performed since 2006 [36-39]. HCV prevalence is especially low below age 45 . Thus, improvements in transfusion practices implemented in China in the mid-1990s, notably prohibition of paid donations of plasma and blood that were associated with mass transmission of $\mathrm{HCV}$ and HIV, appear to have largely controlled the HCV epidemic. Indeed, population-based HCV prevalence [36], and proportion of liver cancer attributed to $\mathrm{HCV}$ [34], appears to be relatively low and decreasing over time in China.

HCV prevalence in women in Tbilisi, Georgia (1.3\%) is compatible with that from a previous population-based survey in which the vast majority of $\mathrm{HCV}$ infections in Tbilisi were observed to occur among male intravenous drug users [40]. Indeed, increasing intravenous drug use is feared to be an important source of recent $\mathrm{HCV}$ transmission in many former Soviet republics [41]. Estimates of $0.8 \% \mathrm{HCV}$ prevalence in Warsaw, Poland are similar to that in a nationwide study of 42,274 women $(0.8 \%$ [42]), and with that modelled from meta-analytical data [43].

No population-based data are available for Algeria, but our HCV prevalence estimates (0.1\%) compare well to the $0.2 \%$ and $0.6 \%$ reported among 1,000 [44] and 3,044 [45] pregnant women, respectively. This would suggest Algeria to have an $\mathrm{HCV}$ prevalence similar to its neighbors Morocco and Tunisia [46], and much lower than in Egypt [2], for which much more populationbased data is available.

No population-based data are available for Nepal, but our $\mathrm{HCV}$ prevalence estimate of $0.2 \%$ compares well to the $0.1 \%$ reported among 2,007 female blood donors [47], suggesting that Nepal has largely escaped an epidemic of HCV to date.

Lastly, this study provides the first report on HCV infection in Guinea, for which the $0.9 \% \mathrm{HCV}$ prevalence is lower than previous regional estimates for West subSaharan Africa (2.8\% [1] and 5.3\% [2]), which are nonetheless very sensitive to the lack of relevant data from this region of the world. Lower HCV prevalence among women aged under 45 years in Guinea may represent a cohort effect of reduced HCV transmission in younger generations.

HCV infection increased with age in most countries, presumably due to accumulating risk of exposure. This confirms steady increases up to the age of 60 years reported in a meta-analysis of age-specific HCV infection from Mongolia and Poland [43], and in large studies in China [36-39].

Given the orientation of the surveys towards studying HPV, questionnaires did not include variables that would be useful to studying specific iatrogenic transmission routes. Nevertheless, to our knowledge, this is the first study to suggest the existence of a possible association between HCV infection and parity, which persisted even after adjustment for center and age, which may represent a risk of $\mathrm{HCV}$ transmission by medical interventions/hospitalizations linked to childbirth. On the other hand, we were able to robustly confirm the absence of sexual transmission of $\mathrm{HCV}$ in the general female population, through the null association with number of sexual partners, and presence of cervical HPV infection, as proxies of sexual intercourse.

Our data arises entirely from females in selected towns, and may not be representative of males or other areas in the same country. In most populations around the world, $\mathrm{HCV}$ prevalence in females has been estimated to be similar or lower than that in males [43]. However, at least Mongolia [43] and China [38] may represent exceptions to this rule. In any case, we propose that our population-based sampling procedures provide a more representative picture than studies limited to typically young pregnant women or blood donors.

HCV genotypes are known to vary between the different worldwide regions represented by this study. Nevertheless, the cross-reactivity of serological assays for NS3 and Core proteins of genotypes $1 \mathrm{a}, 1 \mathrm{~b}$ and $2 \mathrm{a}$ does not suggest that their performance should be affected by the existence of HCV serotypes [7]. Furthermore, the assay 
was shown to be highly reproducible when a large subset of samples were re-tested on a second occasion, and has been well-validated against commercial $\mathrm{HCV}$ tests [7] and for use with dried blood spots [19]. Taken together, we believe that this protocol represents a useful model for obtaining $\mathrm{HCV}$ prevalence data from low- and middle-income settings where data is scarce, for both men and women alike. Indeed, DBS do not require blood centrifugation and allow storage and shipment at ambient temperature, thus facilitating field work for seroepidemiological studies in environments with limited technical infrastructure, and the research serological assay is both high-throughput and cost-effective.

\section{Conclusions}

HCV prevalence varied enormously across the female populations represented in our study. Medical interventions/hospitalizations linked to childbirth may have represented a route of $\mathrm{HCV}$ transmission, at least in some settings, but not sexual intercourse. Combining dried blood spot collection with high-throughput HCV assays can facilitate seroepidemiological studies in LMIC where data is otherwise scarce. Indeed, the availability of population-based HCV estimates is going to become increasingly relevant in the next years, as countries consider the cost and public health priority of going beyond the prevention of $\mathrm{HCV}$ transmission by ensuring safety of medical interventions, towards screen-and-treat approaches that can benefit from a new generation of highly performant oral $\mathrm{HCV}$ treatment regimens [5].

\section{Abbreviations \\ Cl: confidence interval; DBS: dried blood spot; DKFZ: German Cancer Research Center; HCV: hepatitis C virus; HPV: human papillomavirus virus; IARC: International Agency for Research on Cancer; LMIC: low and middle- income countries; MFI: median R-phycoerythrin fluorescence intensity; PR: prevalence ratio}

\section{Acknowledgements}

We would like to thank Vanessa Tenet for data management and analysis.

\section{Funding}

Not applicable.

\section{Availability of data and material}

All data generated or analyzed during this study are included in this published article.

\section{Authors' contributions}

GMC conceived the study, supervised the data analysis and drafted the manuscript, in collaboration with SF. BD, TW and M Pawlita developed and performed the HCV assay. YLQ, DK, DH, NK, NK, SAR, ATS and WZ are the local principal investigators for each of the study centres responsible for acquiring the primary epidemiological data and samples. M Plummer was responsible for estimates of HCV-related liver cancer rates. All authors read, gave feedback and approved the final version of the manuscript.

\section{Competing interests}

The authors declare they have no competing interests.

Consent for publication

Not applicable.

\section{Ethics approval and consent to participate}

All participants signed informed consent forms according to the recommendations of the IARC Ethics Committee, and of the local ethical review committees in each of the participating countries, which also approved each of the original studies.

\section{Author details}

${ }^{1}$ International Agency for Research on Cancer, 150 cours Albert Thomas, 69372 Lyon Cedex 08, France. ${ }^{2}$ Infection, Inflammation and Cancer Program, German Cancer Research Center (DKFZ), Heidelberg, Germany. ${ }^{3}$ Cancer Institute of the Chinese Academy of Medical Sciences, Beijing, China. ${ }^{4}$ IV. Javakhishvili Tbilisi State University, Tbilisi, Georgia. ${ }^{5}$ Institut National de Sante Publique, Algiers, Algeria. ${ }^{6}$ Department of Obstetrics and Gynaecology, Centre Hospitalier Universitaire de Donka, Conakry, Guinea. Infertility and Reproductive Health Research Centre, Shahid Beheshti University of Medical Sciences, Tehran, Iran. ${ }^{8}$ Department of Surgery, The Aga Khan University, Karachi, Pakistan. ${ }^{9}$ Centre de Recherche du CHUM, Département de Médecine Sociale et Préventive Université de Montréal, Quebec, Canada.

${ }^{10}$ Kist Medical College, Lalitpur, Nepal. ${ }^{11}$ The Maria Sklodowska-Curie Memorial Cancer Center and Institute of Oncology, Warsaw, Poland.

Received: 29 November 2016 Accepted: 19 January 2017

Published online: 02 February 2017

\section{References}

1. Mohd Hanafiah K, Groeger J, Flaxman AD, Wiersma ST. Global epidemiology of hepatitis C virus infection: new estimates of age-specific antibody to HCV seroprevalence. Hepatology. 2013;57:1333-42. doi:10.1002/hep.26141.

2. Gower E, Estes C, Blach S, Razavi-Shearer K, Razavi H. Global epidemiology and genotype distribution of the hepatitis C virus infection. J Hepatol. 2014; 61:S45-57. doi:10.1016/j.jhep.2014.07.027.

3. Petruzziello A, Marigliano S, Loquercio G, Cozzolino A, Cacciapuoti C. Global epidemiology of hepatitis $C$ virus infection: An up-date of the distribution and circulation of hepatitis C virus genotypes. World J Gastroenterol. 2016; 22:7824-40. doi:10.3748/wjg.v22.i34.7824.

4. Lozano R, Naghavi M, Foreman K, Lim S, Shibuya K, Aboyans V, et al. Global and regional mortality from 235 causes of death for 20 age groups in 1990 and 2010: a systematic analysis for the Global Burden of Disease Study 2010. Lancet. 2012;380:2095-128. doi:10.1016/s0140-6736(12)61728-0.

5. WHO. Global health sector strategy on viral hepatitis 2016-2021. Geneva: WHO Press; 2016.

6. IARC. 2012. Biological agents. IARC Monogr Eval Carcinog Risks Hum 100B:1475. http://monographs.iarc.fr/ENG/Monographs/vol100B/index.php. Accessed 27 July 2016

7. Dondog B, Schnitzler P, Michael KM, Clifford G, Franceschi S, Pawlita M, et al. Hepatitis C Virus Seroprevalence in Mongolian Women Assessed by a Novel Multiplex Antibody Detection Assay. Cancer Epidemiol Biomarkers Prev. 2015;24:1360-5. doi:10.1158/1055-9965.epi-15-0351.

8. Dai M, Bao YP, Li N, Clifford GM, Vaccarella S, Snijders PJF, et al. Human papillomavirus infection in Shanxi Province, People's Republic of China: a population-based study. Br J Cancer. 2006;95:96-101.

9. Li LK, Dai M, Clifford GM, Yao WQ, Arslan A, Li N, et al. Human papillomavirus infection in Shenyang City, People's Republic of China: A population-based study. Br J Cancer. 2006;95:1593-7.

10. Wu RF, Dai M, Qiao YL, Clifford GM, Liu ZH, Arslan A, et al. Human papillomavirus infection in women in Shenzhen City, People's Republic of China, a population typical of recent Chinese urbanisation. Int J Cancer. 2007;121:1306-11.

11. Dondog B, Clifford GM, Vaccarella S, Waterboer T, Unurjargal D, Avirmed D, et al. Human papillomavirus infection in Ulaanbaatar, Mongolia: a population-based study. Cancer Epidemiol Biomarkers Prev. 2008;17:1731-8.

12. Bardin A, Vaccarella S, Clifford GM, Lissowska J, Rekosz M, Bobkiewicz P, et al. Human papillomavirus infection in women with and without cervical cancer in Warsaw, Poland. Eur J Cancer. 2008;44:557-64.

13. Keita N, Clifford GM, Koulibaly M, Douno K, Kabba I, Haba M, et al. HPV infection in women with and without cervical cancer in Conakry, Guinea. Br J Cancer. 2009;101:202-8.

14. Sherpa AT, Clifford GM, Vaccarella S, Shrestha S, Nygard M, Karki BS, et al. Human papillomavirus infection in women with and without cervical cancer in Nepal. Cancer Causes Control. 2010;21:323-30. 
15. Raza SA, Franceschi S, Pallardy S, Malik FR, Avan BI, Zafar A, et al. Human papillomavirus infection in women with and without cervical cancer in Karachi, Pakistan. Br J Cancer. 2010;102:1657-60.

16. Hammouda D, Clifford GM, Pallardy S, Ayyach G, Chekiri A, Boudrich A, et al. Human papillomavirus infection in a population-based sample of women in Algiers, Algeria. Int J Cancer. 2011;128:2224-9.

17. Alibegashvili T, Clifford GM, Vaccarella S, Baidoshvili A, Gogiashvili L, Tsagareli Z, et al. Human papillomavirus infection in women with and without cervical cancer in Tbilisi, Georgia. Cancer Epidemiol. 2011;35:465-70.

18. Khodakarami N, Clifford GM, Yavari P, Farzaneh F, Salehpour S, Broutet N, et al. Human papillomavirus infection in women with and without cervical cancer in Tehran, Iran. Int J Cancer. 2012;131:E156-61.

19. Waterboer T, Dondog B, Michael KM, Michel A, Schmitt M, Vaccarella S, et al. Dried blood spot samples for seroepidemiology of infections with human papillomaviruses, Helicobacter pylori, Hepatitis C Virus, and JC Virus. Cancer Epidemiol Biomarkers Prev. 2012;21:287-93.

20. Jacobs MV, Walboomers JM, Snijders PJ, Voorhorst FJ, Verheijen RH, Fransen-Daalmeijer N, et al. Distribution of 37 mucosotropic HPV types in women with cytologically normal cervical smears: the age-related patterns for high-risk and low-risk types. Int J Cancer. 2000;87:221-7.

21. Waterboer T, Sehr P, Michael KM, Franceschi S, Nieland JD, Joos TO, et al. Multiplex human papillomavirus serology based on in situ-purified glutathione s-transferase fusion proteins. Clin Chem. 2005;51:1845-53.

22. Doll R, Payne P, Waterhouse J. Cancer Incidence in Five Continents: A Technical Report. Berlin: Springer-Verlag (for UICC); 1966.

23. Plummer M, de Martel C, Vignat J, Ferlay J, Bray F, Franceschi S. Global burden of cancers attributable to infections in 2012: a synthetic analysis. Lancet Glob Health. 2016:4:e609-e616. doi:10.1016/S2214-109X(16)30143-7.

24. Ferlay J, Soerjomataram I, Ervik M, Dikshit R, Eser S, Mathers C, et al. 2013. GLOBOCAN 2012 v1.0, Cancer Incidence and Mortality Worldwide: IARC CancerBase No. 11 [Internet]. on International Agency for Research on Cancer. http://gco.iarc.fr/today/home. Accessed 27 July 2016.

25. Kurbanov F, Tanaka Y, Elkady A, Oyunsuren T, Mizokami M. Tracing hepatitis $\mathrm{C}$ and Delta viruses to estimate their contribution in HCC rates in Mongolia. J Viral Hepat. 2007;14:667-74

26. Tsatsralt-Od B, Takahashi M, Nishizawa T, Inoue J, Ulaankhuu D, Okamoto H. High prevalence of hepatitis $B, C$ and delta virus infections among blood donors in Mongolia. Arch Virol. 2005;150:2513-28.

27. Tserenpuntsag B, Nelson K, Lamjav O, Triner W, Smith P, Kacica M, et al. Prevalence of and risk factors for hepatitis $B$ and $C$ infection among Mongolian blood donors. Transfusion. 2010;50:92-9.

28. Logez S, Soyolgerel G, Fields R, Luby S, Hutin Y. Rapid assessment of injection practices in Mongolia. Am J Infect Control. 2004;32:31-7.

29. Taherkhani R, Farshadpour F. Epidemiology of hepatitis C virus in Iran. World J Gastroenterol. 2015;21:10790-810. doi:10.3748/wjg.v21.i38.10790

30. Hajiani E, Masjedizadeh R, Hashemi J, Azmi M, Rajabi T. Risk factors for hepatocellular carcinoma in Southern Iran. Saudi Med J. 2005;26:974-7.

31. Abdullah F, Pasha H, Memon A, Shah U. Increasing frequency of anti-hcv seropositivity in a cross-section of people in Karachi, Pakistan. Pak J Med Sci. 2011:27:767-70

32. Afzal MS. 2016. Are efforts up to the mark? A cirrhotic state and knowledge about HCV prevalence in general population of Pakistan. Asian Pacific Journal of Tropical Medicine 9:616-618. doi:http://dx.doi.org/10.1016/j.apjtm. 2016.04.013.

33. Qureshi H, Bile KM, Jooma R, Alam SE, Afridi HU. Prevalence of hepatitis B and $C$ viral infections in Pakistan: findings of a national survey appealing for effective prevention and control measures. East Mediterr Health J. 2010; 16(Suppl):S15-23.

34. de Martel C, Maucort-Boulch D, Plummer M, Franceschi S. 2015. Worldwide relative contribution of hepatitis $B$ and $C$ viruses in hepatocellular carcinoma. Hepatology 62:1190-1200. doi:10.1002/hep.27969 [doi].

35. Alavian SM, Haghbin H. Relative Importance of Hepatitis B and C Viruses in Hepatocellular Carcinoma in EMRO Countries and the Middle East: A Systematic Review. Hepat Mon. 2016;16, e35106. doi:10.5812/ hepatmon.35106.

36. Chen Y, Li L, Cui F, Xing W, Wang L, Jia Z, et al. A sero-epidemiological study on hepatitis $C$ in China. Chin J Epidemiol. 2011;32:888-91.

37. Lu J, Zhou Y, Lin X, Jiang Y, Tian R, Zhang Y, et al. General epidemiological parameters of viral hepatitis $A, B, C$, and $E$ in six regions of China: a cross-sectional study in 2007. PLoS One. 2009;4, e8467. doi:10.1371/journal.pone.0008467.
38. Ke X, Liguo Z, Fenyang T, Changjun B, Yefei Z, Minquan C, et al. Rate of infection and related risk factors on hepatitis $C$ virus in three counties of Jiangsu province. Chin J Epidemiol. 2014;35:1212-7.

39. Zhou M, Li H, Ji Y, Ma Y, Hou F, Yuan P. Hepatitis C virus infection in the general population: A large community-based study in Mianyang, West China. Biosci Trends. 2015;9:97-103. doi:10.5582/bst.2015.01033.

40. Stvilia K, Tsertsvadze T, Sharvadze L, Aladashvili M, del Rio C, Kuniholm MH, et al. Prevalence of hepatitis C, HIV, and risk behaviors for blood-borne infections: a population-based survey of the adult population of T'bilisi, Republic of Georgia. J Urban Health. 2006;83:289-98. doi:10.1007/s11524006-9032-y.

41. Kelly JA, Amirkhanian YA. The newest epidemic: a review of HIV/AIDS in Central and Eastern Europe. Int J STD AIDS. 2003;14:361-71. doi:10.1258/ 095646203765371231

42. Walewska-Zielecka B, Religioni U, Juszczyk G, Czerw A, Wawrzyniak Z, Soszynski $P$. Diagnosis of hepatitis $C$ virus infection in pregnant women in the healthcare system in Poland: Is it worth the effort? Medicine (Baltimore). 2016;95, e4331. doi:10.1097/md.0000000000004331.

43. Saraswat V, Norris S, de Knegt RJ, Sanchez Avila JF, Sonderup M, Zuckerman $\mathrm{E}$, et al. Historical epidemiology of hepatitis $\mathrm{C}$ virus $(\mathrm{HCV})$ in select countries - volume 2. J Viral Hepat. 2015;22 Suppl 1:6-25. doi:10.1111/jvh.12350.

44. Ayed Z, Houinato D, Hocine M, Ranger-Rogez S, Denis F. Prevalence of serum markers of hepatitis $B$ and $C$ in blood donors and pregnant women in Algeria. Bull Soc Pathol Exot. 1995;88:225-8.

45. Aidaoui M, Bouzbid S, Laouar M. Seroprevalence of HIV infection in pregnant women in the Annaba region (Algeria). Rev Epidemiol Sante Publique. 2008;56:261-6. doi:10.1016/j.respe.2008.05.023.

46. Fadlalla FA, Mohamoud YA, Mumtaz GR, Abu-Raddad LJ. The epidemiology of hepatitis C virus in the Maghreb region: systematic review and metaanalyses. PLoS One. 2015;10, e0121873. doi:10.1371/journal.pone.0121873.

47. Tiwari BR, Ghimire P, Kandel SR, Rajkarnikar M. Seroprevalence of HBV and HCV in blood donors: A study from regional blood transfusion services of Nepal. Asian J Transfus Sci. 2010;4:91-3. doi:10.4103/0973-6247.67026.

\section{Submit your next manuscript to BioMed Central and we will help you at every step:}

- We accept pre-submission inquiries

- Our selector tool helps you to find the most relevant journal

- We provide round the clock customer support

- Convenient online submission

- Thorough peer review

- Inclusion in PubMed and all major indexing services

- Maximum visibility for your research

Submit your manuscript at www.biomedcentral.com/submit
Biomed Central 